\title{
Anatomical and Clinical Aspects of Horseshoe Kidney: A Review of the Current Literature
}

\author{
Aspectos Anatómicos y Clínicos del Riñón en Herradura: Una Revisión de la Literatura Actual
}

\author{
Krzysztof Balawender ${ }^{1,2}$; Agnieszka Cisek ${ }^{1}$; Ewelina Cisek $^{1}$ \& Stanislaw Orkisz ${ }^{1}$
}

BALAWENDER, K.; CISEK, A.; CISEK, E. \& ORKISZ, S. Anatomical and clinical aspects of horseshoe kidney: A review of the current literature. Int. J. Morphol., 37(1):12-16, 2019.

SUMMARY: Horseshoe kidney (HSK) is the most common kidney malformation. This review analyses the literature surrounding the etiology, morphology and clinical anatomy of these kidney fusion anomalies. A systematic literature search was carried out using the Science Direct and Scopus applications. HSK is characterized by three anatomic abnormalities: ectopia, malrotation and vascular changes. The study put emphasis especially on blood supply and upper urinary tract changes in HSK's patients. Arterial blood supply was analysed not only basing on Graves pattern, but also a new model of supply created on horseshoe kidneys computed tomography was taken into account. In addition, study presents clinical aspects of especially significant pathology of HSK, like hydronephrosis, stones and urinary tract infection. This study focuses also on congenital anomalies associated with horseshoe kidney.

KEY WORDS: Horseshoe kidney; Renal fusion; Kidney vasculature.

\section{INTRODUCTION}

Horseshoe kidney (HSK) is the most common congenital renal fusion anomaly and is characterised by three morphological anomalies: ectopia, malrotation and changes in vascular supply. Jacopo Berengario da Carpi was the first person to describe this abnormality during autopsies in 1522 (Oktem et al., 2008). HSK usually consists of two renal masses fused at their lower poles by a parenchymal or fibrous isthmus (Natsis et al., 2014). The frequency of appearance is 1 per 400-600 births and occurs more often in men (2:1 ratio). The reported incidence of this abnormality in anatomical dissections varies in the literature from $0.15 \%$ to $0.48 \%$. There is no proven genetic determination of HSK, although it has been reported in identical twins and siblings within the same family (Yoshinaga et al., 2002). From the clinical point of view, HSK in adults usually produces no symptoms, but it has important implications with regards to secondary renal pathology such as urinary tract infections, hydronephrosis or stone formation. The incidence of fusion anomalies appears in three age groups: in small children HSKs are diagnosed as part of a combination of malformations, in young adults during diagnosis of delayed menarche as a part of Turner syndrome (Glodny et al., 2009), while detection of HSK in adults is incidental during routine radiological procedures (transabdominal ultrasounds, computed tomography or intravenous pyelography) performed on them for other reasons.
Search of the literature. A systematic search of the literature was carried out using the Science Direct and Scopus applications. The search terms included: "horseshoe kidney", "kidney fusion", "kidney vascular" and "surgery". In total, 41 articles in journals were refreshed. The search was limited to articles in English with no date limit. Finally, 25 references were included in the manuscript.

Morphology and topography of horseshoe kidney. Morphological classification of HSK is based on the renal shape based on the appearance of two fused renal masses (Pawar et al., 2018). The U-shaped HSK is formed by medial fusion. In this configuration, kidneys may be placed in a symmetrical position, U-shaped kidneys are observed in 42 $\%$ of incidences of HSK. Another type, which is a result of lateral fusion relative to the vertebral column, is called Lshaped HSK (Fig 1). This type occurs in $58 \%$ of incidences of HSK (Oktem et al.). The asymmetry is more commonly left dominant (70\%) (Glodny et al.). In over $90 \%$ of cases, fusion between the kidneys occurs at the lower pole; however, we can also observe upper pole fusion resulting in "inverted HSK" (5-10 \%). Kidneys ascend from the pelvis to the mesogastrium during the seventh week of fetal development and reach their final position by the end of the eighth or ninth week (Taghavi et al., 2016). HSK is found more commonly in

\footnotetext{
${ }^{1}$ Morphological Sciences Department of Human Anatomy, Medical Faculty University of Rzeszów Leszka Czarnego $435-615$ Rzeszów, Poland. ${ }^{2}$ Department of Urology, Pope John Paul II Hospital in Zamosc, Poland Al. Jana Pawla II 21 22-400 Zamosc, Poland.
} 


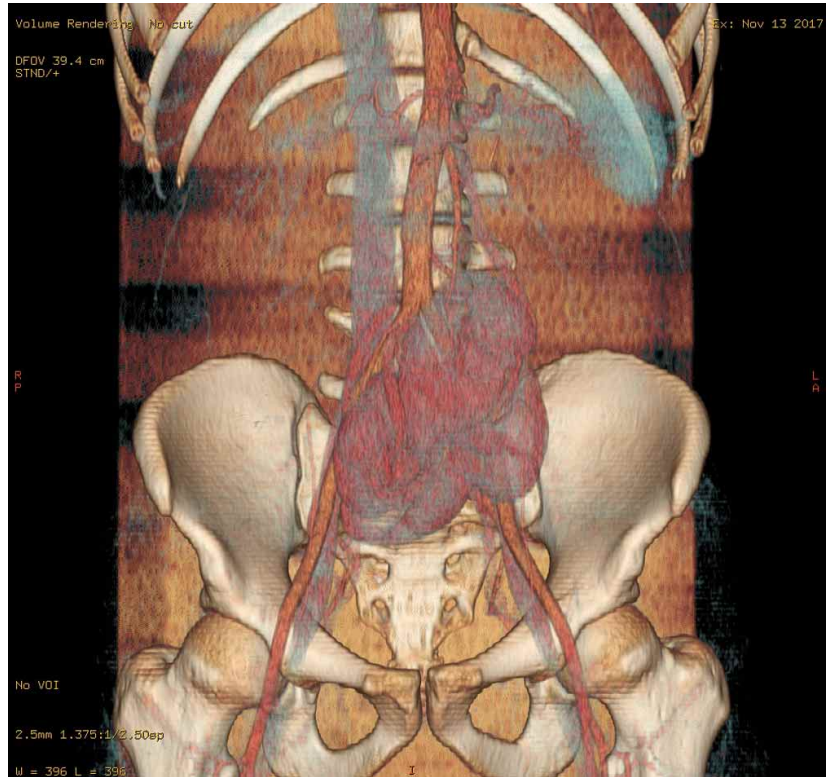

Fig. 1. Coronal reconstruction of axial CT scan of abdomen demonstrating a horseshoe kidney (morphological variant with lateral fusion). Image reproduced with permission from Department of Urology, Pope John Paul II Hospital in Zamosc, Poland.

a lower position than a normally located kidney because the isthmus is prevented from ascending to its normal position by the inferior mesenteric artery (IMA) (O'Brien et al., 2008). The isthmus usually lies under the IMA origin anterior to the large vessels at the level of the third to the fifth lumbar vertebra (Decter et al., 1997). Less commonly, the isthmus is situated posterior to those vessels or runs between them. In $80 \%$ of HSK cases, the isthmus contains renal parenchyma, with 20 $\%$ fibrous tissue (Taghavi et al.). Knowledge about the structure of the isthmus tissue is crucial from clinical point of view in planning HSK surgery, as well as in planning abdominal aorta surgery by laparotomy in vascular surgery.

Vascular system of the horseshoe kidney. Kidney fusion anomalies show great variation in the origin, number and size of renal vessels, depending on where the ascent terminated during development. The vascular pattern of HSK that was proposed by Graves in 1969 nowadays has a rather historical meaning. Graves separated the vascular anatomy of HSK into six groups. In this study, renal arteries can originate from the abdominal aorta, common iliac arteries and the inferior mesenteric artery (FigS. 2,3). The development of imaging techniques allowed a detailed analysis of the vascularisation of HSKs to be performed. Glodny et al. in a retrospective cohort study (level of evidence $2 \mathrm{~b}$ ) analysed more than 200 cases of kidney fusion anomalies and only $5 \%$ of patients had a simple situation of only one artery on each side. Based on these studies, due to the wide range of possible arterial origins that include: common iliac artery (40\%), median sacral artery

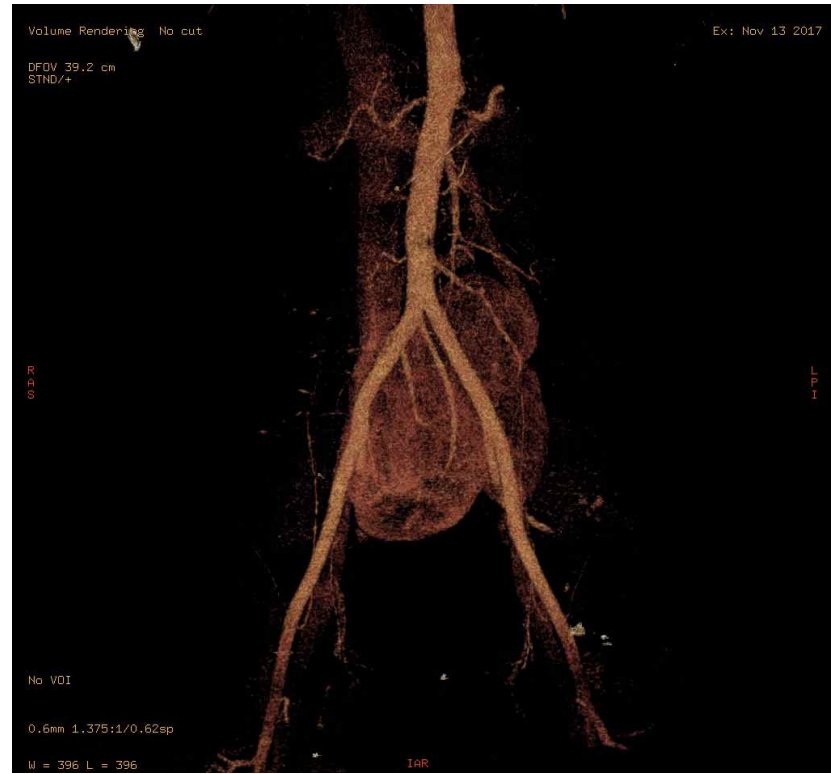

Fig. 2. Arterial supply of male horseshoe kidney. Image reproduced with permission from Department of Urology, Pope John Paul II Hospital in Zamosc, Poland.

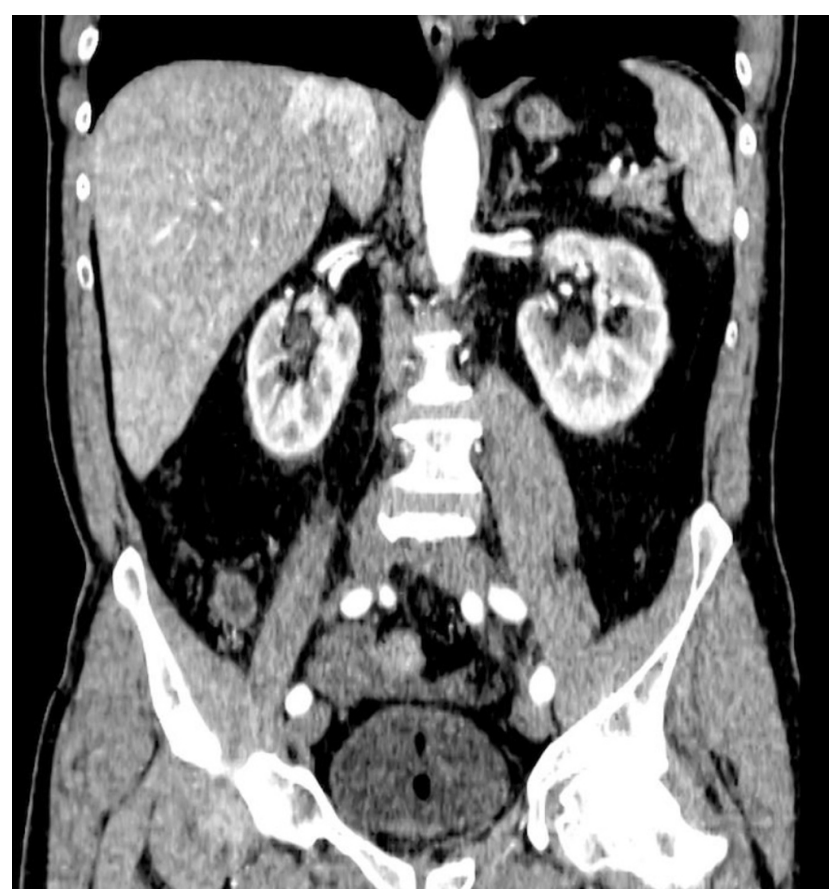

Fig. 3. Coronal reconstruction of axial CT scan shows a horseshoe kidney with a bilateral double renal arteries originate from abdominal aorta. Image reproduced with permission from Department of Urology, Pope John Paul II Hospital in Zamosc, Poland.

$(2.9 \%)$, internal iliac artery $(1.94 \%)$, external iliac artery $(0.97 \%)$, iliolumbar artery $(2.9 \%)$ and phrenic artery $(0.97$ $\%)$. What is more, Glodny et al. firstly made allowance for arteries that supplied portions of the contralateral kidney (this 
occurs in approximately $25 \%$ of HSK cases). The blood supply of the isthmus also has some variability: it may receive blood from the main renal artery, from the abdominal aorta (originating above or below the isthmus), the common iliac artery or the inferior mesenteric artery (Mano et al., 2016). Considering the embryological aspect, the isthmus blood supply reflects vascular changes of the developing kidneys during the course of kidney ascent from the pelvic to the abdominal position (Raman et al., 2018).

The incidence of kidney vein anomalies in HSKs is also high (23\%) (Pawar et al.). Frequently, HSK entails inferior vena cava (IVC) abnormalities, such as double, left and pre-isthmic IVC. Variations of IVC anatomy are observed ten times more frequently than in the general population (5.7\%) (Ichikawa et al., 2012). There is some data from case study reports about double IVC or pre-isthmic IVC (Kehagias et al., 1999). Moreover, HSK can be related to double superior vena cava due to the fact that their incidences are associated with cardiovascular malformations (Greenwood et al., 1976). Glodny et al. made general conclusions about the horseshoe kidney vasculature based on a retrospective cohort study. The cranial kidney vessels on both sides are located typically - the second artery on the left side is precaval, the second vein on the left side is usually retro-aortic. The caudal kidney vessels are located more ventral and often have more variation.

Changes in the upper urinary tract of horseshoe kidneys. Upper urinary tracts of HSKs are characterised by the great variation in their number and origin. Typically, calyces are located in the upper two-thirds of each kidney, but an external calyx or an independent ureter may drain the isthmus (Pawar et al.) (Fig. 4). The data from case study reports only shows anatomical variation of urinary tracts associated with HSK. Shen et al. (2012) described an HSK case with retrocaval ureters. Ongeti et al. (2011) presented bilateral ureteral duplication. Ureters usually end in the bladder, but they can also be found in an ectopic position (Cascio et al., 2002). Changes in a ureter's position in an HSK are a direct cause of secondary hydronephrosis and uretero-pelvis junction (UPJ) obstruction. UPJ obstruction can be the result of the high insertion of ureters into the renal pelvis, causing delayed pelvic emptying (Mano et al.). Rotation abnormalities of kidneys are also a significant cause of ureter obstruction. Normally, during the 6-8th week of gestation, the kidney hilum rotates from an anterior to a medial position. One of the anatomic abnormalities which is observed in HSKs is malrotation. The most common occurrences are incomplete rotations or non-rotations, but we can also observe hyper-rotation or reverse rotation. Nephrolithiasis, occurring in $16 \%$ to $60 \%$ of HSK cases (Glodny et al.) and urinary tract infections are clinical consequences of upper urinary tract abnormalities in an HSK.

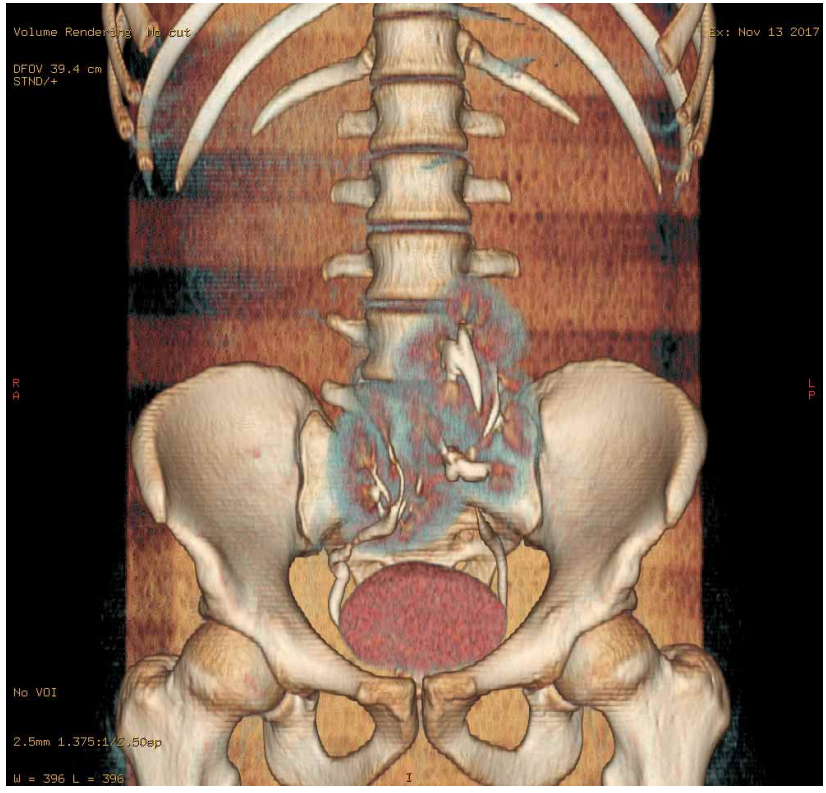

Fig. 4. Coronal reconstruction of axial CT scan of abdomen shows CT urography. Image reproduced with permission from Department of Urology, Pope John Paul II Hospital in ZamoSc, Poland.

Clinical manifestation of horseshoe kidney. HSK is usually asymptomatic and a horseshoe kidney is often discovered as an incidental finding. When symptoms are present, they usually occur because of obstruction, stones or infection. The most common finding in HSK is UPJ obstruction, which occurs in approximately $35 \%$ of HSK patients (O'Brien et al.). UPJ obstruction is secondary to a high insertion of ureters into the kidney pelvis, which causes delayed pelvic emptying. Another cause of obstruction can be the crossing of the ureter over the HSK isthmus (Costa et al., 2004). A diagnosis of UPJ obstruction is made based on a CT urography or intravenous pyelography with a typical appearance of a large pelvis with a high-riding ureter in the pelvis. There are plenty of treatment options for clinically significant UPJ obstruction in HSK. Surgical technique includes pyeloureteroplasty, which nowadays is performed mostly using laparoscopic techniques. During these procedures, the obstructed UPJ area is excised and a new junction is created. The division of the isthmus has rather historical meaning because it is associated with an increased risk of serious complication, such as haemorrhage or renal infarction.

Another significant consequence of HSK is nephrolithiasis. The prevalence of stone disease in HSK is in the range 16-60\%. Based on Pawar et al. a meta-analysis of the estimated pooled incidence of kidney stones is $36 \%$ (95 $\%$ confidence interval $[\mathrm{CI}])$ in adults with HSK. Kidney stones are less common in the paediatric population with HSK with an estimated pooled incidence of $3 \%(95 \% \mathrm{CI})$. The incidence of kidney stones in HSK patients is much higher than in the 
general adult populations (36\% vs $7 \%$ ). The etiology of stone disease in HSK is multicausal. HSK is related to an atypical position of the ureter in the renal pelvis and an usually highly placed UPJ. Another causes are metabolic factors (hypercalciuria, hyperoxaluria, hyperuricosuria and hypocitraturia) which are common in HSK patients and the coexistence of HSK with medullary sponge kidney (a known cause of high-risk stone disease). Pawar et al. also assessed the type of kidney stones in HSK stone formers. About 89.2 $\%$ of kidney stones were calcium-based stones, $4.2 \%$ were struvite stones, $3.8 \%$ uric acid stones and $2.8 \%$ had other causes. Nephrolithiasis in HSK patients is often multiplied by the risk of large staghorn stones. Treatments are similar to those for a normal kidney. Extracorporeal Shock Wave Lithotripsy (ESWL) or Retrograde Intrarenal Surgery (RIRS) is usually used as a surgical treatment option. Percutaneous Nephrolitothrypsy (PCNL) as a endourological treatment for staghorn stones in HSK patient may be difficult to perform because of the different orientation of kidney calyx. A lower pole approach is taken when possible in a normal kidney because of the lower incidence of complications. In an HSK patient, a percutaneous approach is difficult due to the medial location of the calyx, so a cranial and lateral approach is more often required (Kehagias et al.). Eryildirim et al. (2017) assessed the efficacy and safety of two different techniques PCNL versus RIRS - in the management of stones in patients with HSK. Stone-free rates (about $80 \%$ after 1 week period) and the percentage of cases with residual fragments were comparable in both techniques. Complication rates were found to be similar in both groups. Thus PCNL and RIRS could be safe and effective minimally invasive procedures for kidney stone removal in patients with HSK. An alternative technique in the management of kidney stones in HSK can be a laparoscopic approach. In a prospective randomised study, Fawzi et al. (2017) compared Transperitoneal Laparoscopic Pyelolithotomy (TPLP) and RIRS for the treatment of kidney stones in HSK patients. Based on the study, TPLP was an effective technique with higher stone-free rates; however, RIRS had merits - less invasive, shorter operative time and lower complication rates (Fawzi et al.).

Horseshoe kidney is notably predisposed to urinary tract infections (Natsis et al., 2005). Infection occurs as a result of a combination of reflux disease, stasis and stone formation and is an important cause of death. It is found in up to onethird of patients with HSK (Cascio et al.). Ascending infection is the most common type, usually caused by vesicoureteral reflux, which is presented in approximately $50 \%$ of HSK patients (O'Brien et al.).

A variety of benign and malignant tumours are associated with HSK. The increase in malignancy is thought to be secondary to teratogenic factors present at birth $\left(\mathrm{O}^{\prime}\right.$ Brien et al.). The most common type of tumour is renal cell carcinoma, which constitutes $45 \%$ of all HSK tumours (Fazio et al., 2003). Transitional cell carcinoma accounts for $20 \%$ of tumours in patients with HSK (three to fourfold relative increased risk with HSK). This increased risk comes from chronic infection, stones and associated obstruction in the upper urinary tract. The incidence of carcinoid and Wilms tumours is also higher than in the general population (Talpallikar et al., 2001) HSK causes a 62-fold increase in the risk of renal carcinoid tumour in comparison with the normal population (Krishnan et al., 1997). Wilms tumour accounts for $28 \%$ of malignant tumours ( $\mathrm{O}^{\prime}$ Brien et al.). Both of these malignancies have a predilection for location in the isthmus, probably related to teratogenesis during embryological development (Krishnan et al.).

Surgical treatment of tumours in HSK, due to the location of the mass, limited mobilisation of the fused kidney and its multiple arterial blood supplies, is difficult and usually needs treatment in an advanced urological centre. Nowadays, minimally invasive surgical techniques including laparoscopic and robot-assisted approaches are recommended (Raman et al.). Patients with a kidney cortical tumour may be treated with partial nephrectomy with limited blood loss and preservation of kidney function. However, the overall complication rate is relatively high (43\%) (Mano et al.).

Horseshoe kidney, due to the location in the lower part of abdomen and the presence of the isthmus across the midline, is associated with a higher risk of blunt abdominal trauma (Murphy et al., 1996).

HSK is not well protected by the ribs and may be injured across the lumbar vertebral column (O'Brien et al.). Thus, after lower abdominal trauma in HSK patient, especially with associated haematuria, radiological investigation to look for hematoma and other injuries is necessary.

Congenital anomalies associated with horseshoe kidney. HSK is associated with many congenital anomalies, especially central nervous system, skeletal or chromosomal abnormalities. $60 \%$ of Turner syndrome and $20 \%$ of Down and Edwards syndrome patients have a HSK (Natsis et al., 2005). There are case study reports showing spina bifida associated with HSK patients (Taghavi et al.). Henley et al. described supernumerary kidney with HSK (Natsis et al., 2014). Other anomalies may include undescended testis and hypospadias (O’Brien et al.).

CONCLUSION. HSK is the most common congenital anomaly of the urinary tract. These kidney fusion anomalies are mostly asymptomatic; however, significant symptoms, 
especially hydronephrosis, stones and infections, constitute important causes of death in HSK patients. An abnormal kidney is usually related to a range of anatomical changes. Vessel relations and supply are highly variable. Furthermore, horseshoe kidneys are characterised by various ureteric configurations. All of these abnormalities have important clinical implications.

BALAWENDER, K.; CISEK, A.; CISEK, E. \& ORKISZ, S. Aspectos anatómicos y clínicos del riñón en herradura: Una revisión de la literatura actual. Int. J. Morphol., 36(4):12-16, 2018.

RESUMEN: El riñón en herradura (RH) es la malformación renal más común reportada en la literatura. Esta revisión analiza la literatura que rodea la etiología, morfología y anatomía clínica de esta anomalía de fusión renal. Se realizó una búsqueda sistemática de la literatura utilizando las aplicaciones Science Direct y Scopus. El riñón en herradura se caracteriza por tres anomalías anatómicas: ectopía, malrotación y cambios vasculares. El estudio puso énfasis especialmente en el suministro de sangre y los cambios del tracto urinario superior en los pacientes con RH. El suministro de sangre arterial se analizó no solo basándose en el patrón de Graves, sino que también se tuvo en cuenta un nuevo modelo de suministro creado en los riñones en herradura. Además, el estudio presenta aspectos clínicos de patología especialmente significativa de RH, como hidronefrosis, cálculos e infección del tracto urinario. Este estudio se centró también en las anomalías congénitas asociadas con el riñón en herradura.

PALABRAS CLAVE: Riñón en herradura; Fusión renal; Vasculatura renal.

\section{REFERENCES}

Cascio, S.; Sweeney, B.; Granata, C.; Piaggio, G.; Jasonni, V. \& Puri, P. Vesicoureteral reflux and ureteropelvic junction obstruction in children with horseshoe kidney: treatment and outcome. J. Urol., 167(6):2566-8, 2002 .

Costa, R. P.; Schaal, C. H. \& Navarro, F. C. Neoplasia in horseshoe kidney with pyelic fusion and crossed single ureter. Int. Braz. J. Urol., 30(4):31920, 2004.

Decter, R. M. Renal duplication and fusion anomalies. Pediatr. Clin. North Am., 44(5):1323-41,1997.

Eryildirim, B.; Kucuk, E. V.; Ozturk. M.; Senkul, T.; Tuncer, M.; Tahra, A.; Turan, T.; Ates, F.; Yilmaz, O.; Sabuncu, K. \& Sarica, K. Safety and efficacy of Percutaneous Nephrolithotomy (PCNL) vs Retrograde Intrarenal Surgery (RIRS) in the management of stones located in horseshoe kidneys: A critical comparative evaluation. Eur. Urol. Suppl., 16(7):e2572, 2017.

Fawzi, A.M.; Sakr, A.; Eliwa, A.; Omran, M.; Youssef, M.; Desoky. E. \& Seleem, M. Transperitoneal laparoscopic pyelolithotomy versus retrograde intrarenal surgery for treatment of renal pelvis stones in horseshoe kidneys: A prospective randomized study. Eur. Urol. Suppl., 16(3):e741, 2017.

Fazio, L.; Razvi, H. \& Chin, J. L. Malignancy in horseshoe kidneys: review and discussion of surgical implications. Can. J. Urol., 10(3):1899-904, 2003.

Glodny, B.; Petersen, J.; Hofmann, K. J.; Schenk, C.; Herwig, R.; Trieb, T.; Koppelstaetter, C.; Steingruber, I. \& Rehder, P. Kidney fusion anomalies revisited: clinical and radiological analysis of 209 cases of crossed fused ectopia and horseshoe kidney. B. J. U. Int., 103(2):224-35, 2009.

Greenwood, R. D.; Rosenthal, A. \& Nadas, A. S. Cardiovascular malformations associated with congenital anomalies of the urinary system. Observations in a series of 453 infants and children with urinary system malformations. Clin. Pediatr. (Phila.), 15(12):1101-4,1976.

Ichikawa, T.; Sekiguchi, T.; Kawada, S.; Koizumi, J.; Endo, J.; Yamada, Y.; Ito, C.; Sugiyama, M.; Terachi, T.; Usui, Y.; Torigoe, K. \& Imai, Y. Study of the association between an anomalous superior vena cava and horseshoe kidney. Circ. J., 76(5):1253-8, 2012.

Kehagias, D. T.; Gouliamos, A. D. \& Vlahos, L. J. Horseshoe kidney associated with anomalous inferior vena cava. Eur. Radiol., 9(5):935-6, 1999.

Krishnan, B.; Truong, L. D.; Saleh, G.; Sirbasku, D. M. \& Slawin, K. M. Horseshoe kidney is associated with an increased relative risk of primary renal carcinoid tumor. J. Urol., 157(6):2059-66, 1997.

Mano, R.; Hakimi, A. A.; Sankin, A. I.; Sternberg, I. A.; Chevinsky, M. S. \& Russo, P. Surgical treatment of tumors involving kidneys with fusion anomalies: A contemporary series. Urology, 98:97-102, 2016.

Murphy, J. T.; Borman, K. R. \& Dawidson, I. Renal autotransplantation after horseshoe kidney injury: a case report and literature review. J. Trauma, 40(5):840-4, 1996.

Natsis, K.; Piagkou, M.; Skotsimara, A.; Protogerou, V.; Tsitouridis, I. \& Skandalakis, P. Horseshoe kidney: a review of anatomy and pathology. Surg. Radiol. Anat., 36(6):517-26, 2014.

Natsis, K.; Tsitouridis, T.; Totlis, T.; Loutradis, Ch.; Tarazi, L.; Papastergiou, Ch.; Koebke, J. Horseshoe kidney. Anatomical, radiological, embryological approach and clinical importance of eleven cases. Hell. Nephrol., 17:3119, 2005.

O'Brien, J.; Buckley, O.; Doody, O.; Ward, E.; Persaud, T. \& Torreggiani, W. Imaging of horseshoe kidneys and their complications. J. Med. Imaging Radiat. Oncol., 52(3):216-26, 2008.

Oktem, H.; Gozil, R.; Calguner, E.; Bahcelioglu, M.; Mutlu, S.; Kurkcuoglu, A.; Yucel, D.; Senol, E.; Babus, T. \& Kadioglu, D. Morphometric study of a horseshoe kidney. Med. Princ. Pract., 17(1):80-3, 2008.

Ongeti, K. W.; Ogeng'O, J. \& Saidi, H. A horseshoe kidney with partial duplex systems. Int. J. Anat. Var., 4:55-6, 2011.

Pawar, A. S.; Thongprayoon, C.; Cheungpasitporn, W.; Sakhuja, A.; Mao, M. A. \& Erickson, S. B. Incidence and characteristics of kidney stones in patients with horseshoe kidney: A systematic review and meta-analysis. Urol. Ann., 10(1):87-93, 2018.

Raman, A.; Kuusk, T.; Hyde, E. R.; Berger, L. U.; Bex, A. \& Mumtaz, F. Roboticassisted laparoscopic partial nephrectomy in a horseshoe kidney. A case report and review of the literature. Urology, 114:e3-e5, 2018.

Shen, H. L.; Yang, P. Q.; Du, L. D.; Lü, W. C. \& Tian, Y. Horseshoe kidney with retrocaval ureter: one case report. Chin. Med. J. (Engl.), 125(3):543-5, 2012.

Taghavi, K.; Kirkpatrick, J. \& Mirjalili, S. A. The horseshoe kidney: Surgical anatomy and embryology. J. Pediatr. Urol., 12(5):275-80, 2016.

Talpallikar, M. C.; Sawant, V.; Hirugade, S.; Borwankar, S. S. \& Sanghani, H. Wilms' tumor arising in a horseshoe kidney. Pediatr. Surg. Int., 17(5-6):4656, 2001.

Yoshinaga, K.; Kodama, K.; Tanii, I. \& Toshimori, K. Morphological study of a horseshoe kidney with special reference to the vascular system. Anat. Sci. Int., 77(2):134-9, 2002.

Corresponding author:

Krzysztof Balawender

Morphological Sciences

Department of Human Anatomy

Medical Faculty University of Rzeszów

Leszka Czarnego 4 35-615

Rzeszów

POLAND

Email: balawender82@gmial.com

Received: 06-05-2018

Accepted: 12-09-2018 